\title{
¿De arriba hacia abajo o de abajo hacia arriba? Un análisis crítico de la planificación del desarrollo en América Latina
}

\author{
José Ignacio DIEZ \\ Departamento de Economía \\ Universidad Nacional del Sur \\ jdiez@uns.edu.ar \\ Ricardo Raúl GUTIÉRREZ \\ Departamento de Economía \\ Universidad Nacional del Sur \\ rgutier@criba.edu.ar \\ Andrés PAZZI \\ Naciones Unidas \\ andrespazzi80@gmail.com
}

Organización para la Agricultura y la Alimentación (FAO)

Recibido: 27-02-2013

Aceptado: 02-11-2013

\section{RESUMEN}

El trabajo examina las transformaciones ocurridas en las políticas de desarrollo económico durante el siglo $\mathrm{XX}$, poniendo especial énfasis en los cambios sufridos por la disciplina conocida como planificación del desarrollo. Específicamente, se analizan los cambios de perspectiva que atravesaron esta área del conocimiento, desde los enfoques denominados de "arriba hacia abajo" a aquellos conocidos como de "abajo hacia arriba". En este sentido, se describen los principales rasgos y características de los enfoques de crecimiento equilibrado, desequilibrado y de la teoría de los polos de crecimiento. A su vez, también se analizan los fundamentos de la teoría del desarrollo económico local, sus principales fortalezas y debilidades poniendo especial atención en la experiencia latinoamericana. Por último, se plantea la necesidad de avanzar en la construcción nuevos marcos conceptuales que permitan superar controversias y aprender de la experiencia histórica.

Palabras clave: políticas de desarrollo económico; planificación del desarrollo; desarrollo local; América Latina. 


\title{
Top-down or bottom-up? \\ A critical analysis of developmental planning in Latin America
}

\begin{abstract}
This article explores the transformations in developmental planning policies throughout the $20^{\text {th }}$ century - with a special focus on the changes occurred within the discipline known as "developmental planning"- To be more precise, changes in the approaches within this field of study will be ined -including "top-down" and "bottom-up" perspectives-. To that end, I will review the defining features of approaches such as "balanced growth", "unbalanced growth" and the "theory of growth poles". Likewise, I will deal with the main tenets of the theory of local economic development, its strengths and weaknesses, where I will pay special attention to the Latin American experience. Finally, this article will ponder over the necessity to construct new conceptual frameworks that help to transcend controversies and to learn from past experiences.
\end{abstract}

Key words: economic development policies; developmental planning; local development; Latin America.

\section{De cima para baixo ou de baixo para cima? Uma análise crítica da planificação do desenvolvimento em América Latina}

\begin{abstract}
RESUMO
$\mathrm{O}$ trabalho examina as transformações ocorridas nas políticas de desenvolvimento económico durante o século XX, dando ênfase às mudanças sofridas pela disciplina conhecida como planificação do desenvolvimento. Especificamente, analisam-se as mudanças de perspectivas que atravessaram esta área do conhecimento, a partir dos enfoques denominados "de cima para baixo" àqueles conhecidos como "de baixo para cima". Neste sentido, descrevem-se os principais traços e características dos enfoques de crescimento equilibrado, desequilibrado e da teoria dos polos de crescimento. Por sua vez, também se analisam os fundamentos da teoria do desenvolvimento econômico local e seus pontos altos e baixos, dando especial atenção à necessidade de avançar na construção de novos marcos conceituais que permitam superar controvérsias e aprender pela experiência histórica.
\end{abstract}

Palavras-chave: políticas de desenvolvimento econômico; planificação do desenvolvimento; desenvolvimento local; América Latina.

\section{REFERENCIA NORMALIZADA}

Díez, José Ignacio; Gutiérrez, Ricardo Raúl, y Pazzi, Andrés (2013) “¿De arriba hacia abajo o de abajo hacia arriba? Un análisis crítico de la planificación del desarrollo en América Latina". Geopolítica(s). Revista de estudios sobre espacio y poder, vol. 4, núm. 2, 199-235.

SUMARIO: Introducción. 1. Las transformaciones de la política de desarrollo económico. 1.1. Desde las políticas de laissez-faire hasta el círculo vicioso de la pobreza. 1.2. Desarrollo equilibrado, desequilibrado y polos de crecimiento. 2. La corriente regional participativa. 2.1. La corriente regional participativa y el paradigma del emprendedorismo. 2.2. La corriente regional participativa y el paradigma de la nueva gestión municipal. 2.3. La corriente regional participativa y el paradigma de la sociedad civil organizada. 3. Críticas y reflexiones sobre la corriente regional participativa. Alcances y limitaciones. Conclusiones: la experiencia latinoamericana y la necesidad de construcción de un nuevo enfoque capaz de superar controversias. Bibliografía. 


\section{Introducción}

A partir de la pretensión de los individuos de mejorar sus niveles de bienestar, naturalmente la problemática del desarrollo económico está en el centro de la actividad humana. Los logros macroeconómicos a nivel de un país o del mundo, no significan necesariamente un mejoramiento del estándar de vida de toda la población. La problemática de la distribución de la riqueza, y en el caso del desarrollo económico, de los beneficios del mismo, presenta una total vigencia y se encuentra en el centro del debate relativo al diseño de políticas públicas en cualquier parte del mundo.

En términos históricos, durante el siglo XIX y principios del siglo XX, existían enormes diferencias de bienestar entre los distintos grupos sociales tanto dentro como entre países. Sin embargo, en la doctrina económica y política, estas diferencias eran consideradas casi "naturales", y se creía que sólo se solucionarían a partir del esfuerzo personal y/o del ahorro de las personas involucradas en los procesos económicos.

Esta concepción, que se manifestaba insuficiente para lograr el bienestar general, dio origen a conflictos permanentes. A raíz de esto, los Estados nacionales, comenzaron a dejar de ser "gendarmes" para actuar en un sentido proactivo sobre la realidad. De esta acción surge la intervención del estado en la economía y en la sociedad, buscando alterar los ritmos de acumulación del capital, el crecimiento económico, la distribución del ingreso y el consumo. A su vez, las intervenciones destinadas a incrementar la capacidad productiva, y por ende la producción de los países, fueron atravesando a lo largo de los años por diversas etapas en las que fue cobrando cada vez más relevancia la necesidad de solucionar disparidades regionales y la concentración territorial de actividades y de población.

A partir de una extensa revisión bibliográfica, el presente trabajo analiza la transformación que han sufrido las políticas de desarrollo económico, desde aquellas diseñadas e implementadas por los gobiernos nacionales hasta las más actuales o recientes, donde cobra importancia el accionar de los gobiernos municipales, los empresarios locales y/o de la sociedad civil.

Habitualmente, el primer tipo de políticas se define como concebidas e instrumentadas "desde arriba": esto se debe a que son diseñadas por técnicos y burócratas en oficinas ministeriales, en base planteos teóricos e información secundaria, pero sin un involucramiento real con las problemáticas propias del terreno en el cual han de ser ejecutadas. Por su parte, las más actuales o recientes presentan una perspectiva "desde abajo"; ya que incorporan en todo el proceso a los actores del territorio, de tal forma que los mismos se transforman en sujetos creadores de la política pública y simultáneamente en objeto de la misma.

Centrando el estudio sobre la experiencia latinoamericana, el artículo intenta hacer un balance sobre la planificación económica regional basada en estas dos concepciones desde una perspectiva histórica, evaluando tanto alcances como limita- 
ciones. En este sentido, se presentan en forma estilizada los principales enfoques teóricos vigentes en cada momento histórico y sus resultados, analizados con una mirada crítica. En primer lugar, se describen los cambios ocurridos en las políticas públicas desde fines del siglo XIX hasta la mitad de siglo XX. En este punto se realiza una introducción a la discusión de la problemática regional a partir de hechos y circunstancias que desencadenaron un cambio en el papel del Estado en la economía, desde posiciones liberales hacia planteos de tipo intervencionistas, que permitieron posteriormente justificar y dar sentido a las acciones de desarrollo regional.

En segundo lugar, se analiza la controversia entre los autores adherentes a la estrategia de crecimiento equilibrado y aquellos partidarios del crecimiento desequilibrado, además del intento de síntesis detrás de la noción de polo de crecimiento. En este apartado se presentan los ejes centrales sobre los cuales se estructura cada una de estas estrategias pensadas e instrumentadas desde "arriba", haciendo principal hincapié en los resultados generales que se observaron en América Latina luego de la aplicación de la idea acuñada por Francois Perroux.

En tercer término, se discuten los rasgos distintivos de la corriente de planificación denominada regional participativa, la cual originó un quiebre o cambio de perspectiva en la orientación de la política de desarrollo territorial, involucrando a los actores locales en los procesos de crecimiento y cambio estructural. A partir del reconocimiento de ciertos ejes comunes que comparten las distintas posturas englobadas dentro de esta corriente, se discuten las que, a juicio de los autores, han tenido mayor predicamento en América Latina: aquella que asocia el desarrollo local-regional con el municipalismo, la que destaca el papel del empresario local en el crecimiento del territorio y la que supone que el desarrollo es una consecuencia necesaria de la existencia de una organización social dinámica.

Respecto a esta cuestión, resulta relevante reconocer la diversidad de visiones y acepciones que puede asumir el término desarrollo local. La variedad de procesos y experiencias que se aglutinan bajo este amplio paraguas reclama necesariamente un esfuerzo de discriminación entre los distintos enfoques que lo impulsan.

Haber advertido y desagregado la multiplicidad de sentidos que orientan la acción local, para luego rescatar estos tres criterios relevantes en la experiencia Latinoamericana, han significado un esfuerzo conceptual de importancia para ordenar un área de conocimiento que se funda sobre un objeto de estudio novedoso.

Por último, se dedica un apartado del trabajo a criticar la corriente regional participativa y sus tres visiones fundamentales, discutiendo los supuestos sobre los cuales se sustenta el enfoque y otras cuestiones de naturaleza instrumental.

A modo de conclusión, se plantea la necesidad de diseñar un nuevo abordaje de la problemática del desarrollo territorial en América Latina, que tenga en cuenta los aspectos particulares de economías en vías de desarrollo y que sea capaz, a su vez, de sintetizar los aspectos positivos de las distintas visiones de la planificación, superando la antinomia tradicional arriba-abajo abajo-arriba. 


\section{Las transformaciones de la política de desarrollo económico}

\subsection{Desde las políticas de laissez-faire hasta el círculo vicioso de la pobreza}

Las corrientes principales de la literatura sobre políticas de desarrollo económico, que se generaron a partir de la Segunda Guerra Mundial centraban la problemática en lo que podría denominarse la "economía nacional". Los objetivos e instrumentos y los análisis costo-beneficio, impacto y factibilidad se referían a la totalidad de la nación, y ponían esencialmente la cuestión en términos de la responsabilidad del Estado central.

Esto puede interpretarse como un efecto de la forma de considerar la política económica a partir de los análisis keynesianos, pero, en realidad, la economía desde sus inicios planteó la problemática en términos de esta esfera o nivel de gobierno, por considerar el desarrollo una cuestión dependiente de la máxima autoridad.

Mientras predominaron las ideas liberales, el accionar público se limitaba a garantizar el libre funcionamiento del mercado, la vigencia de los contratos y la seguridad, actividades que deben prestarse en forma homogénea en todo el territorio nacional.

Por su parte, a partir del auge del keynesianismo, se introducen nuevas funciones para el Estado en materia económica, también circunscriptas a dicha esfera: esencialmente, las políticas fiscales y monetarias.

Resulta obvio que la política monetaria debe ser manejada en forma nacional; en lo que respecta a la política fiscal, dadas las condiciones históricas de la época, sólo este nivel del Estado estaba en condiciones de gestionar tributos y gasto público en magnitud significativa.

Las políticas fiscales de inspiración keynesiana, al menos en sus primeras manifestaciones, estaban dirigidas a salir de las recesiones y fundamentalmente consideraban la situación de países con un grado de desarrollo y nivel de vida aceptables, pero con problemas derivados del funcionamiento del capitalismo liberal.

Así se reconocían situaciones de desigualdad en la distribución de la riqueza en los países desarrollados, y diferencias en el bienestar de las poblaciones (provocadas por el desempleo), situaciones que se consideraban muy difíciles (o imposibles) de solucionar a través de políticas de mercado.

Por ello surgen dos concepciones de diferente nivel en materia de política de gasto: el intervencionismo del Estado con el objetivo de salir de la recesión, que se vincula a la importancia de la política fiscal como instrumento idóneo para modificar los comportamientos de las economías estancadas a través del impulso a la demanda agregada; y la responsabilidad del Estado por el bienestar de la población (gastos en salud, educación, vivienda, etc.) lo que necesariamente está vinculado a políticas activas de gran impacto por parte de los gobiernos. 
Históricamente, la actuación de los Estados en estos ámbitos se planteó, dada la magnitud de esa intervención, como una responsabilidad esencialmente de los gobiernos nacionales.

Asimismo, no era tampoco despreciable la influencia que en aquellos años la centralización y dirección de la economía socialista ejercía, fundamentalmente en Europa, en el sentido indicado. Es preciso tener en cuenta que la experiencia rusa de intervención en la economía, previa a la Segunda Guerra Mundial y durante la guerra, resultaba con fuerte predicamento en la época.

A su vez, los logros de la integración alemana en el siglo XIX y la puesta en marcha de la economía del bienestar sin ninguna duda representaban un logro del centralismo. Cuando buena parte de los países de Europa avanzaron en responsabilizar al Estado por el bienestar de los ciudadanos, dicho compromiso naturalmente se radicó en el Estado nacional, al menos como responsable principal.

Luego de la Segunda Guerra Mundial, cuando se hizo evidente la existencia de regiones del mundo que estaban atrasadas y eran pobres, esta idea del Estado central como agente necesario y eficiente capaz de solucionar los problemas económicos ganó terreno y se expandió por el globo.

Se consideraba que las zonas atrasadas y marginales tanto de países industrializados como de países pobres podían desarrollarse a partir de grandes proyectos de inversión ${ }^{1}$. Estos proyectos, que generalmente necesitaban de un financiamiento importante, en contextos de países que no disponían de ahorro interno significativo o con ahorro interno fragmentado y de difícil concentración, sólo podían recaer en la responsabilidad de los Estados nacionales, que se transformaban en los receptores de los fondos, del asesoramiento internacional y de la creación de burocracias para su administración.

Durante aquellos años (fines de los 1950) surgió una importante literatura tendente a justificar y dar sentido a estas acciones de desarrollo regional. En términos teóricos, los escritos formulados por diversos autores sostenían que a través de una estrategia intervencionista del Estado central era posible alcanzar una aceleración del proceso de crecimiento regional gracias a efectos de difusión y arrastre sobre diversos sectores productivos (Nurske, 1954; Hirschman, 1957; Myrdal, 1957; Rosenstein-Rodan, 1943; Perroux 1955; Boudeville, 1965).

\footnotetext{
${ }^{1}$ Una de las primeras iniciativas de esta naturaleza en países capitalistas (anterior a la segunda guerra) fue la implementada por la Tenessee Valley Authority (TVA) en los Estados Unidos durante el año 1933 para el desarrollo de cuencas hidrográficas. Estos proyectos consistían en la realización de obras hidroeléctricas y de infraestructura básica, generalmente complementadas por programas de desarrollo agropecuario. La experiencia del TVA tuvo una amplia difusión y repercusión en América Latina, como ejemplo de que era posible una planificación de tipo democrática. Entre los proyectos de desarrollo regional influidos por la TVA se encuentran la Corporación del Santa (Perú, 1943), la Comisión del Valle de San Francisco (Brasil, 1948) y la Corporación del Valle del Cauca (Colombia, 1954).
} 
Este grupo de intelectuales, muy influenciado por la idea de la existencia de un círculo vicioso de pobreza, planteaba que el principal problema de las regiones subdesarrolladas era el nivel de acumulación y la debilidad del estímulo a la inversión, debido principalmente a la precariedad de funcionamiento y de magnitud de los mercados, lo cual no se solucionaba espontáneamente. En este sentido, autores como Myrdal (1957) sostenían que los mecanismos de mercado lejos de mostrar una tendencia a eliminar las diferencias entre regiones, las acentuaban.

Esta creencia debilitó el reconocimiento de los mercados libres como instituciones eficientes para el desarrollo, y golpeó las alternativas liberales como opciones aceptables de política, acentuando el intervencionismo de los gobiernos en todos los ámbitos de la actividad económica, y social.

En su libro Teoría económica y regiones subdesarrolladas el autor afirma que:

No existe normalmente tal tendencia hacia la autoestabilización automática del sistema social. El sistema no se mueve por sí mismo hacia ningún tipo de equilibrio de fuerzas, sino que está constantemente alejándose de tal posición. Normalmente un cambio no da lugar a cambios compensadores, sino que por el contrario da lugar a efectos concurrentes que mueven el sistema en la misma dirección que el cambio original, impulsándolo más lejos. Esta causación circular hace que todo el proceso social tienda a convertirse en acumulativo y que a menudo adquiera velocidad a un ritmo acelerado (Myrdal, 1957: 53, traducción propia).

En términos generales, este enfoque planteaba que la demanda es la que apuntala el crecimiento económico, y que es su expansión la que impulsa la inversión; ésta, a su vez, aumenta el producto y los ingresos y posteriormente el consumo y el gasto, dando lugar a una segunda fase de inversión y así sucesivamente.

Así, si en una determinada región hay ausencia de efectos impulsores, la demanda de capital permanece a niveles relativamente bajos limitando las posibilidades de crecimiento, y por lo tanto, se favorece la transferencia de recursos hacia regiones desarrolladas.

\subsection{Desarrollo equilibrado, desequilibrado y polos de crecimiento}

Si bien el aporte de Myrdal no pretendía convertirse en una teoría del desarrollo, propone un esquema muy simple que muestra los mecanismos a través de los cuales tienden a ampliarse las diferencias económicas entre regiones.

Este problema, denominado de "insuficiencia de capital", fue ampliamente debatido a fines de los 1950, dando origen esencialmente a dos grupos de economistas que planteaban estrategias de desarrollo opuestas entre sí: los partidarios del crecimiento equilibrado versus los adherentes al crecimiento desequilibrado. 
Entre los adherentes al primer grupo, se ponía especial énfasis en el efecto de ingreso de las inversiones, capaz de ampliar el mercado interno de las regiones. Desde este punto de vista toda inversión en una economía generaba un aumento de ingresos que se traducía posteriormente en un incremento del gasto, ampliando el mercado interno nacional o regional. Esta ampliación del mercado volvía atractiva la radicación de nuevas inversiones complementarias en el efecto ingreso a la anterior.

En relación a este punto, Nurske (1954) afirmaba que:

La tasa de crecimiento de cualquier industria está inevitablemente condicionada por la tasa de crecimiento de otras industrias, aunque naturalmente algunas crecerán más a prisa que otras puesto que las elasticidades (ingreso) de la demanda y la oferta variarán según los diferentes productos. Mediante la aplicación de capital a un grupo amplio de actividades, el nivel general de eficiencia económica se eleva y el mercado se amplía (Nurske, 1954: 21).

Planteada de este modo, la estrategia para que el conjunto de industrias sean complementarias en el sentido del efecto ingreso debía ser promover la radicación de empresas que produzcan bienes de consumo final y, en especial, bienes de consumo de los asalariados. A través de este mecanismo, se buscaba alcanzar el despegue de las regiones.

Por otro lado, los partidarios del crecimiento desequilibrado hacían hincapié en la complementariedad técnica de los proyectos. Este enfoque se basaba en la idea de que las inversiones inducen nuevas inversiones a través de presiones de demanda (insumos) o disponibilidades de oferta (productos que pueden utilizarse como insumos en nuevos sectores).

Esta noción de crecimiento llevaba a proponer como recomendación de política la concentración de capitales en aquellos sectores que maximizaban los efectos de eslabonamiento.

Desde esta óptica, Albert Hirschman (1957) planteaba que en los territorios menos favorecidos debían canalizarse los esfuerzos de inversión en aquellos sectores que tuviesen una demanda final asegurada. Luego, la mayor densidad de manufacturas de demanda final proporcionaría un mercado suficiente para los de demanda intermedia. Este mismo razonamiento debía aplicarse a las inversiones de infraestructura que servían de soporte a las actividades productivas y, en general, a todo el capital fijo social, siempre y cuando ya se hubiesen superado ciertos umbrales mínimos, sin los cuales el desarrollo económico no puede siquiera plantearse como objetivo (Espina, 1994).

Detrás de esta lógica, los multiplicadores de Leontieff constituían un instrumento idóneo capaz de medir los requerimientos directos e indirectos del aumento de la producción de un sector. 
Por su parte, en materia de política de desarrollo regional, ambos enfoques teóricos se sintetizaron detrás del concepto de "polo de desarrollo" o "polo de crecimiento", término acuñado originariamente por Francois Perroux.

A partir de un estudio sobre la región de Lieja, Paelinck (1963) caracterizó un polo de crecimiento en función de sus efectos de la siguiente forma:

Constituye un polo de crecimiento una industria que por los flujos de productos y de ingresos que puede generar condiciona el desarrollo y el crecimiento de industrias técnicamente ligadas a ella (polarización técnica), determina la prosperidad del sector terciario por medio de los ingresos que engendra (polarización de ingresos) y produce un aumento del ingreso regional por la concentración progresiva de nuevas actividades en una zona dada, mediante las perspectivas de disponer allí de ciertos factores de la producción (polarización psicológica y geográfica) (Paelinck,1963: 6).

La publicación del mencionado trabajo de Paelinck (1963), y posteriormente, el libro de Boudeville (1965) sobre los espacios económicos, dieron inicio a una profusa literatura sobre el tema, haciendo que este modelo normativo se difundiese y penetrase en el ámbito de los planificadores regionales en forma generalizada; a partir de entonces, fueron escasas las estrategias de desarrollo regional impulsadas desde el gobierno central que omitieran la incorporación en forma explícita o implícita de alguna propuesta de implantación y desarrollo de polos de crecimiento.

Por otro lado, pese a su generalizada aceptación y difusión entre los intelectuales vinculados a la planificación del desarrollo regional, los resultados de la aplicación de la política fueron poco exitosos.

En términos generales, los proyectos surgidos al calor de estas ideas se transformaron en enclaves típicos con importantes fugas hacia centros industriales dominantes de países desarrollados, sin que se produjese nunca la ansiada polarización técnica. Además, algunas investigaciones realizadas para casos de polos de crecimiento en América Latina pusieron en evidencia que su funcionamiento no condujo a una elevación generalizada del nivel de ingresos regional ni a un mejoramiento de su distribución en la respectiva región, lo que significa que no llegaron a desencadenarse los procesos de polarización de ingresos. Por último, también se ha podido comprobar que tampoco se produjo la esperada propagación de efectos positivos sobre el área de influencia del polo, sino que, en muchos casos, la gravitación del nuevo núcleo industrial en expansión ocasionó una disminución relativa de las actividades productivas y de la población respectiva ${ }^{2}$.

\footnotetext{
${ }^{2}$ Existen varios documentos que analizan el fracaso de polos de desarrollo en América Latina. Travieso (1971) analiza el caso del Polo de crecimiento implementado en la ciudad de Guyana en Venezuela y sostiene que "lo que se esperaba que impulsara el desarrollo regional, en la situación actual, debido al predominio de los encadenamientos externos, genera estancamiento regional y marginalidad urbana, como consecuencia de la incapacidad de las economías dependientes para crear complejos industriales" (Travieso
} 
Rápidamente estos resultados negativos de política pusieron en evidencia la necesidad de efectuar consideraciones respecto al lugar geográfico donde se desenvolvían las inversiones. Las mismas parecían ser más exitosas en espacios geográficos que reunían ciertas características, determinados recursos de tipo económicos, determinadas instituciones u organizaciones y/o prácticas sociales. Si bien era obvio que estos elementos no se encontraban distribuidos uniformemente en el espacio nacional, tal condición de espacialidad no había sido considerada previamente por los hacedores de política.

Estos nuevos elementos producen un quiebre o cambio de perspectiva en la visión del desarrollo regional. En términos generales, el desarrollo deja de ser concebido como algo que podía imponerse desde arriba, es decir, desde el Estado central a través de inversiones en capital físico, para pensarse como algo que debía ser construido a partir de las capacidades de los actores locales.

Nace entonces en el escenario Latinoamericano, una nueva corriente de planificación del desarrollo que puede denominarse como "regional participativa" (De Mattos, 1986).

\section{La corriente regional participativa}

Esta corriente de pensamiento tiene como antecedente más significativo dos trabajos pioneros de Eduardo Neira Alva $(1972,1974)$ en los cuales se trabajan algunas líneas estratégicas para el desarrollo regional en base a experiencias de negociación nacional-regional que el autor había conocido directamente en Brasil (De Mattos, 1986).

A partir de estos resultados, se han formalizado propuestas tales como las de "planificación negociada" (Boisier, 1979), "planificación multifuncional" (Boisier, 1982), "planificación participativa" (Haddad, 1980) o "paradigma de abajo hacia arriba" (Stöhr y Todling, 1979; Stöhr 1981).

Más recientemente se han acuñado conceptos como "desarrollo local" (Arocena, 1997; Buarque, 1999) o "desarrollo endógeno”3 (Boisier, 1993; Vázquez Barquero,

1971: 22). Por otro lado, otros analizan el caso del Polo de Crecimiento de Lázaro Cárdenas-Las Truchas en México llegando a conclusiones similares a la anterior (Restrepo, 1984; Zapata 1985).

${ }^{3}$ El concepto de desarrollo endógeno es de origen europeo, y de hecho, la popularización del término en el continente americano tiene que ver con los fluidos contactos entre investigadores locales y consultores españoles e italianos. En este sentido, muchos autores consideran que los problemas de desarrollo en América Latina son similares a aquellos que existían en regiones del sur de Europa, por lo tanto, los diagnósticos sobre lo que debe hacerse suelen ser los mismos. Sin embargo, no han sido similares los resultados en materia de política, ya que en América Latina predominan estrategias de intervención mucho más precarias, que terminan por desvirtuar incluso algunos preceptos de las teorías originales. En este sentido, el desarrollo endógeno a la "americana" suele ser bastante diferente del europeo. Por otro lado, existen enfoques más 
1995) para intentar explicar el proceso que sufren las localidades y regiones sometidas a estas técnicas de intervención territorial.

Si bien las propuestas planteadas por esta corriente tienen diferencias entre sí, existen ciertas coincidencias centrales que permiten sintetizar sus objetivos fundamentales (Cuadro 1).

\section{Cuadro 1. Coincidencias centrales de la corriente regional participativa}

\begin{tabular}{|c|c|c|c|}
\hline & Rasgo distintivo & Propuestas que engloba & Objetivos centrales \\
\hline $\begin{array}{l}\text { Corriente } \\
\text { Regional } \\
\text { Participativa } \\
\text { (De Mattos) }\end{array}$ & $\begin{array}{l}\text { Confianza en las } \\
\text { propias fuerzas para } \\
\text { promover el desarrollo } \\
\text { económico (self } \\
\text { reliance). }\end{array}$ & $\begin{array}{l}\text { Planificación Negociada } \\
\text { (Boisier,1979) } \\
\text { Planificación Multifuncional } \\
\text { (Boisier, 1982). } \\
\text { Planificación Participativa } \\
\text { (Haddad, 1980). } \\
\text { Paradigma Abajo-Arriba (Stöhr } \\
\text { y Todling, 1978). } \\
\text { Desarrollo local (Arocena, 1997) } \\
\text { Desarrollo Endógeno (Boisier, } \\
\text { 1993; Vázquez Barquero, 1995). }\end{array}$ & $\begin{array}{l}\text { - Retención del excedente } \\
\text { generado a escala local. } \\
\text { - Crecimiento } \\
\text { principalmente en base a } \\
\text { recursos propios. } \\
\text { - Promoción de } \\
\text { empresarios locales. } \\
\text { - Fomento de la } \\
\text { innovación en el territorio. } \\
\text { - Mayor participación de } \\
\text { los actores locales. }\end{array}$ \\
\hline
\end{tabular}

Fuente: Elaboración propia.

El principal rasgo distintivo de los adherentes a esta corriente es su propensión a privilegiar la acción organizada e impulsada desde la propia parte del territorio que se busca beneficiar. En general, la idea de confianza en las propias fuerzas o selfreliance constituye la columna vertebral de esta manera de concebir la acción social. La exaltación de los recursos existentes en el territorio y la recurrente mención a la necesidad de su potenciación, constituyen el eje fundamental del discurso.

En cuanto a los objetivos centrales, en primer lugar se plantea como necesario retener la mayor proporción posible del excedente generado a nivel regional, de tal forma que se promueva el desarrollo y el crecimiento económico. En este sentido, se considera fundamental lograr un cierto grado de cerramiento espacial selectivo, que permita limitar aquellas transferencias que conducen a una reducción de la potencialidad de crecimiento en base a los esfuerzos y recursos propios (Stöhr,

recientes emparentados con estas teorías que también resaltan el papel de los actores locales en la promoción del desarrollo económico. Entre los mismos se puede citar el de "competitividad sistémica" (Esser Hillebrand Messner y Stamer), el de "distritos industriales" (Pyke; Becattini, Camagni, Sengenberger) y el de "medio innovador" (millieu innovateur) (Maillat, Perrin), entre otros. Estos enfoques también de origen europeo, no tienen todavía, a juicio de los autores, una incidencia importante en América Latina. 
$1981)^{4}$; desde este punto de vista, el empresario regional se constituye en una suerte de vedette del proceso de crecimiento económico territorial.

A su vez, dentro de esta idea de retener los excedentes generados, existe una creciente apelación a la necesidad de innovar, por considerar que el progreso técnico es el instrumento más idóneo para incentivar el poder de mercado en las firmas locales y de esta forma maximizar la tasa de ganancia.

En segundo lugar y pese a las consideraciones anteriormente realizadas, la mayor parte de los autores adherentes a esta visión del desarrollo desplazan el centro del análisis de los aspectos productivos (fundamentalmente de carácter industrial) y espaciales (básicamente referidos a componentes urbanos) hacia el papel que cumplen o deberían cumplir los actores centrales de los respectivos procesos sociales regionales.

En relación a este punto, Barreiro (1988) sostiene que "los actores locales son simultáneamente motor y expresión del desarrollo local". A su vez, Boisier manifiesta:

La planeación del desarrollo regional es primero que todo una actividad social, en el sentido de que es una responsabilidad compartida por varios actores sociales: el Estado, desde luego, por varias y conocidas razones; y la propia región en cuanto a comunidad regional, polifacética, contradictoria y difusa a veces, pero comunidad al fin, localmente específica y diferenciada. Sin la participación de la región como un verdadero actor social, la planeación regional sólo consiste — como por lo demás lo prueba la experiencia histórica- en un procedimiento de arriba hacia abajo para asignar recursos financieros o de otra índole entre espacios arbitraria o erróneamente llamados "regiones" (Boisier, 1985: 11).

Como puede observarse, esta corriente de pensamiento tiende a situar en el nivel regional el origen y la gestión de las acciones principales requeridas para mejorar la situación de las regiones atrasadas. En este sentido, el nuevo enfoque destaca la necesidad de aumentar la capacidad de negociación de las regiones, así como de ampliar los niveles de participación en ellas, conjuntamente con la promoción de un mayor poder decisorio del estado local en materia económica.

\footnotetext{
${ }^{4}$ El cerramiento espacial selectivo propone un conjunto de políticas que permitan canalizar los efectos "drenaje" (backwash) de carácter económico, social y político a fin de facilitar una mayor equidad espacial en las condiciones de vida. Tales políticas presuponen, a su vez, varios requisitos: a) la ampliación de las políticas espaciales más allá de la economía para considerar explícitamente los procesos sociales y políticos; b) la reformulación del concepto negativo de fricción de distancia a uno positivo ligado a la estructura de un sistema decisional espacialmente desagregado; c) una mayor atención a las actividades no mercantiles y no institucionales y a los requerimientos de la pequeña escala humana y de las relaciones con el medio; d) un cambio en los poderes decisionales desde las actuales unidades sectoriales (verticales) a unidades territoriales (horizontales).
} 
Estos postulados resultan coincidentes con las transformaciones sufridas por los Estados nacionales a partir de la consolidación del proceso de globalización y, fundamentalmente en América Latina, con la aparición de las políticas del consenso de Washington — de fuerte injerencia en los años 1980 y los 1990-, que han incentivado una mayor descentralización de las decisiones públicas.

Por último, entre los rasgos comunes a las diversas propuestas de esta corriente, importa destacar el papel protagónico que atribuyen a la región, concebida como una suerte de conglomerado mancomunado (vía concertación o pacto social) de fuerzas sociales, estructuradas a partir de organizaciones de la sociedad civil que llegan a constituir una especie de sujeto colectivo capaz de diseñar y conducir un proyecto político de desarrollo económico para el territorio en cuestión.

Estos dos elementos, descentralización y organización civil, sumados a la perspectiva empresarial, han dado origen a una creciente literatura basada en estudios de casos que intenta explicar el desarrollo regional en América Latina a partir de, ya sea, una mayor intervención del Estado local en materia económica o de una sociedad movilizada capaz de generar planes y proyectos de fuerte impacto en el territorio.

\subsection{La corriente regional participativa y el paradigma del emprendedorismo}

Dentro de la corriente regional participativa, se destaca, en primer término, el enfoque que tiende exaltar la importancia de generar empresariado como elemento clave en la motorización del desarrollo. Esta perspectiva encuentra sus raíces en los autores clásicos de la economía como Richard de Cantillon, a quien se le atribuye los primeros trabajos en los que se destaca la figura del empresario como agente de crecimiento. Posteriormente, las Escuelas Neoclásica y Austríaca serían determinantes en la evolución del concepto.

Para los autores neoclásicos, el emprendedor constituye un agente dotado de talento para administrar y coordinar los factores productivos (Lucas, 1988), con tolerancia al riesgo (Kihlstrom y Laffont, 1979), capacidad para apropiarse de nuevas oportunidades rentables (Holmes y Schmitz, 1990) y que basa su crecimiento en la innovación (Aghion y Howitt, 1992).

En este enfoque, el progreso técnico constituye una fuente inagotable de ingresos, destacándose el impacto que genera en la estructura productiva debido a la incorporación de nuevas tecnologías.

Dentro de la Escuela Austríaca, Knight une la función empresarial con la incertidumbre y le asigna al emprendedor la función de asumir los riesgos que se generan cuando intervienen la inteligencia y la capacidad de generar nuevos negocios. En este sentido, Kirzner (1973) sostiene que la actividad empresarial nace de condiciones de desequilibrio en los mercados, causadas por los diferentes planes de consumo y ahorro que poseen los individuos y es el empresario quien trata de captar 
estas discrepancias y resolverlas con su accionar. Para este autor, la función del empresario consiste en detectar oportunidades de negocios e inversión, que terminan favoreciendo finalmente el equilibrio en los mercados.

Posteriormente, Joseph Schumpeter (1942) realiza uno de los aportes más relevantes en este campo al describir al emprendedor como el factor clave en el ciclo económico, entendiéndolo como un agente fundamental en los procesos de acumulación de capital y en la generación de progreso técnico.

Más recientemente en el tiempo, la literatura sobre emprendedorismo comenzó a destacar la figura del entrepreneur como indicador del desarrollo regional. De esta manera, en la escena académica se desarrollan conceptos como "comunidad empresaria", "emprendedor rural" o "emprendedor local" para destacar esta cuestión (Müller, 2011).

De acuerdo a esta perspectiva, Wennekers y Thurik (1999) sostienen que de la interacción entre la noción de emprendedorismo y la idea de desarrollo local se han realizado contribuciones en tres grandes áreas de la economía: a nivel del individuo, a nivel de las empresas y a nivel mesoeconómico. A nivel individual, los estudios se dedicaron a analizar la predisposición psicológica de las personas a emprender, considerando como dicha inclinación incide en la creación de empresas. A su vez, estos trabajos rescatan la existencia de elementos institucionales y culturales que pueden favorecer o no las acciones emprendedoras (Callejón, 2003; Baltar, 2010).

A nivel empresarial se vincula al emprendedorismo con el desarrollo económico, con el propósito de explicar la injerencia de la actividad emprendedora en el desempeño de una región. Las dimensiones consideradas a nivel regional se asocian al crecimiento de la demanda, la aglomeración de empresas y la densidad del contexto urbano (Baltar, 2010). Bajo esta lógica, aquellas regiones que experimentan una alta actividad económica atraen nuevos emprendimientos, elevando la competencia y complementariedad de actividades productivas territoriales (Bosma y Schutjens, 2009).

A nivel mesoeconómico nuevamente se destaca la incidencia que tienen los factores institucionales y culturales en la generación de nuevos emprendimientos, y se vincula la actividad empresarial con la innovación tecnológica en productos y procesos productivos. Desde esta perspectiva, las innovaciones se traducen en un incremento de la capacidad competitiva, mecanismo selectivo por el cual las empresas que incorporan cambios tecnológicos pueden adaptarse a los cambios en el entorno y, de esta manera, permanecer en los mercados.

Como resulta evidente, todos los factores descriptos anteriormente afectan al desarrollo de los territorios, situación que ha dado origen a la diferenciación entre las denominadas regiones emprendedoras y aquellas que no lo son (Florida, 2009).

A su vez, estos elementos de carácter teórico han impactado notablemente en el diseño de políticas públicas que tiene por objetivo promover las capacidades emprendedoras e incentivar la innovación en los espacios locales. 
En términos generales, la idea primordial que se encuentra detrás las mismas es la exaltación de la figura del emprendedor como único agente capaz de generar riqueza. Dada esta condición de partida, se promueve a la clase empresarial como ejemplo de éxito social y se enfatizan los valores que guían su accionar como elementos claves para liderar el proceso de desarrollo económico y social del territorio. En este sentido, se generan condiciones para lograr un mayor bienestar del empresariado local, esperando que, detrás de una mayor rentabilidad de dicho sector se produzca una suerte de "efecto derrame" que impacte positivamente sobre toda la comunidad.

Por su parte, la importancia que cobra la condición de empresario para el desarrollo, lleva a destacar en el seno del cuerpo social todas aquellas habilidades personales que favorezcan la posible emergencia de tal condición, bajo la óptica de suponer que "cualquier persona de la comunidad es un emprendedor en potencia".

En América Latina, han surgido diversos programas para la formación de emprendedores incentivados por autoridades locales que se encuentran guiados por estas premisas. Estas iniciativas incluyen la conformación de foros para discutir la problemática entrepreneur, la realización de capacitaciones en el diseño de planes de negocio, el otorgamiento de premios a la creatividad empresarial y la constitución de fondos para microcréditos. A su vez, se ha dado origen incluso a instituciones especializadas en atender esta problemática. Constituye un ejemplo de esta cuestión, la Universidad Provincial del Sudoeste (UPSO) en Argentina, que tiene por objetivo formar profesionales con vocación emprendedora.

\subsection{La corriente regional participativa y el paradigma de la nueva gestión munici- pal}

La evolución que ha sufrido el concepto de desarrollo regional a lo largo de los años no es sólo fruto de una mejor interpretación de las causas que lo determinan, sino que a su vez está íntimamente vinculado a los cambios que el proceso de globalización ha provocado sobre la estructura del Estado y sobre la sociedad en su conjunto. Según García Delgado (1997), la emergencia del municipio como nuevo actor del desarrollo se origina en la crisis del denominado Estado de bienestar y en la aparición del Estado postsocial.

En América Latina, este proceso se inicia a partir del agotamiento del modelo sustitutivo de importaciones, que es el correlato periférico de la crisis del keynesianismo en los países centrales.

De acuerdo a la literatura referida al tema, desde mediados de los 1970 las economías nacionales sufrieron sucesivos procesos de estanflación (recesión económica más inflación) y de déficit fiscal y endeudamiento que no pudieron resolverse con los mecanismos tradicionales de intervención del Estado central sobre la demanda agregada y el gasto público; esto obligó a la dirigencia política a efectuar 
fuertes políticas de ajuste y apertura hacia el mercado internacional, en un intento de frenar la estampida de precios.

En materia económica, el proceso de apertura provocó un ajuste productivo en las distintas regiones que se tradujo posteriormente en aumento del desempleo, caída del producto bruto, desindustrialización, concentración del capital y de la propiedad y pérdida de mercados.

En el marco de este proceso, se produjo a su vez, una fuerte descentralización de funciones y un traspaso de competencias a niveles inferiores del Estado como mecanismo de reducción del déficit del Estado nacional; esta situación derivo en una delegación de hecho de la política de desarrollo regional en la municipalidades.

En este sentido, Cuervo (1998) sostiene que:

El enfoque local del desarrollo es una respuesta a los problemas del desempleo y desorganización económica causados por la decadencia industrial y las deslocalizaciones. Después del fracaso relativo de los proyectos organizados y aplicados por organismos públicos nacionales, la idea de utilizar procedimientos locales ha ido ganando vigencia (Cuervo, 1998: 21).

Dicha delegación surgió en un contexto de modernización de las estructuras municipales, revisión de los instrumentos estatales tradicionales de fomento de la actividad productiva y reorganización de las relaciones con los actores sociales y privados.

A su vez, los cambios e intervenciones que se dieron en la estructura administrativa municipal buscaron incorporar modelos y comportamientos propios de la empresa privada, destacándose la gestión por resultados, la orientación hacia el cliente, la gestión de contratos y la gestión estratégica (Von Haldenwang, 2000). Estas transformaciones apuntan esencialmente a mejorar la calidad de los servicios que perciben los ciudadanos/clientes, incorporando reformas administrativas y elementos de competencia en su prestación, de acuerdo al grado de complejidad del servicio. Además, se establecieron mecanismos de seguimiento y evaluación de los mismos basados en criterios de calidad total.

Por otro lado, la participación en el diseño e implementación de políticas públicas se instrumenta a través del concepto de "planificación estratégica" y la noción de "cooperación público-privada". Según Cotorruelo Menta (2001), la planificación estratégica puede concebirse como un proceso participativo que involucra a los principales actores políticos, económicos y sociales de la comunidad y que tiene como objetivo elaborar un diagnóstico compartido sobre los aspectos claves del desarrollo competitivo a escala local.

La técnica supone tareas de mediación y concertación de intereses diversos los cuales buscan integrarse en base a objetivos comunes asignando prioridades; la misma se encuentra inspirada en conceptos oriundos del planeamiento empresarial, originalmente sistematizados en la Escuela de Negocios de Harvard. Dicha práctica 
tiene como uno de sus ejes centrales la definición de las actividades económicas (naturaleza, generación de rentas y empleo y efectos sobre la distribución del ingreso y el ecosistema) que van a ser el motor del proceso de cambio estructural (Calatrava Requena, 1992).

Por otro lado, la "cooperación público-privada" (public-private partnership) supone la asociación voluntaria entre actores públicos y privados con el fin de concentrar recursos organizativos, técnicos y materiales en la solución de problemas complejos ligados a la competitividad del territorio. Uno de los objetivos principales de este tipo de iniciativas es coordinar actuaciones, reducir incertidumbre y asimetrías de información entre los distintos actores y proveer bienes públicos que de otra manera no se ofrecerían; son ejemplos de este tipo de cooperación las agencias de desarrollo local, las incubadoras de empresas o las corporaciones de desarrollo, entre otros.

En cuanto a las políticas tendientes a fomentar el desarrollo económico local, Von Haldenwang (2000) hace una clasificación de las mismas dividiéndolas en dos tipos: las que se dirigen a crear infraestructuras locales o políticas de primera generación y las que trabajan principalmente sobre aspectos cualitativos de la competitividad territorial y urbana o políticas de segunda generación.

Entre las primeras, se encuentran aquellas que apuntan a mejorar redes de transporte y comunicaciones (rutas, puertos, aeropuertos, etc.), las que se orientan a crear un suelo acondicionado para la radicación de empresas y las que promueven la construcción de instalaciones de servicios básicos, entre otras.

Dentro de las segundas, Díez (2004) identifica al menos 6 tipos de prácticas gubernamentales que impactan directamente sobre la economía local: la oferta de servicios empresariales y el fomento de proyectos productivos, los programas de financiamiento para micro y pequeñas empresas, los proyectos que promueven la cooperación y las redes interfirma, los programas que apuntan a crear sistemas territoriales de información, aquellos que fomentan la capacitación de recursos humanos y por último, los que otorgan incentivos tributarios a la radicación de empresas.

Estas medidas de política actúan sobre el territorio promoviendo fertilidad (nacimiento y consolidación de nuevas empresas) y atractividad (captación de inversiones extranjeras) de tal forma de acumular capital e incentivar el crecimiento económico.

Por último, diversos organismos internacionales se han encargado de compilar y difundir las buenas prácticas existentes en la materia como un ejemplo de modernización a seguir para los municipios tradicionales. En el caso particular de América Latina, el Banco Mundial y la CEPAL destacan los casos de las ciudades de Rafaela y Córdoba en Argentina; el municipio de Buena Vista en Bolivia; Curitiba, Río Branco, Quixadá y Tupandí en Brasil; Rancagua en Chile; Medellín en Colombia; Jalisco en México, e Iló en Perú. El Cuadro 2 muestra el número total de buenas 
prácticas registradas y la cantidad de municipios involucrados para cuatro países Americanos.

Cuadro 2. Buenas Prácticas Municipales registradas por gobiernos de América Latina

\begin{tabular}{||l|l|l|l|l|l|}
\hline Países & $\begin{array}{c}\text { Número total } \\
\text { de municipios }\end{array}$ & $\begin{array}{c}\text { Número de } \\
\text { Buenas } \\
\text { Prácticas }\end{array}$ & $\begin{array}{c}\text { Porcentaje } \\
\text { de buenas } \\
\text { prácticas } \\
\text { sobre total } \\
\text { de } \\
\text { Municipios }\end{array}$ & $\begin{array}{c}\text { Nunicipios con } \\
\text { buenas } \\
\text { prácticas }\end{array}$ & $\begin{array}{c}\text { Porcentaje } \\
\text { municipios con } \\
\text { buenas } \\
\text { prácticas sobre } \\
\text { el total de } \\
\text { municipios }\end{array}$ \\
\hline Argentina & 2.171 & 138 & $6.35 \%$ & 100 & $4.6 \%$ \\
\hline México & 2451 & 120 & $4.89 \%$ & 87 & $4.89 \%$ \\
\hline Chile & 341 & 97 & $28.4 \%$ & 65 & $19.06 \%$ \\
\hline Colombia & 1088 & 31 & $2.84 \%$ & 31 & $1.2 \%$ \\
\hline
\end{tabular}

Fuente: Montecinos (2005)

Si bien los números de buenas prácticas registradas en los distintos países es aún bajo (Argentina 4.6\%, México 3.5\%, Colombia 2.8\%, Chile 19.06\%), existe un discurso imperante que promueve la traslación de políticas que otrora caían sobre la esfera de incumbencia nacional hacia los municipios. En este sentido, se expande en forma creciente una idea generalizada entre los principales círculos intelectuales vinculados con la gestión pública de que los gobiernos municipales deben estar en condiciones de brindar prestaciones de igual calidad que el estado central, pero mejorando su impacto y eficiencia a raíz de la cercanía con el ciudadano.

2.3. La corriente regional participativa y el paradigma de la sociedad civil organizada

En forma simultánea y concomitante al enfoque municipalista del desarrollo local surge una vertiente participativa de carácter más culturalista que busca resignificar el papel de los actores individuales y colectivos y los rasgos de la organización social donde estos se desenvuelven como factores determinantes de las potencialidades de desarrollo económico en el territorio. Este enfoque sostiene esencialmente que la diferencia de desarrollo entre los pueblos viene dada por su capacidad de acción colectiva, la cual se encuentra estimulada por una cultura de compromiso y colaboración que puede encontrarse activa o latente en el territorio y que resulta de interés potenciar para alcanzar los fines deseados.

De acuerdo a esta perspectiva, la debilidad de la economía local es fruto de limitaciones en el capital social comunitario entendido éste como "actitudes de con- 
fianza que se dan en combinación con conductas de reciprocidad y cooperación" (Durston, 2002: 5). Según Bastiaensen (2001), el capital social comunitario contribuye al desarrollo económico local a través de al menos 5 mecanismos:

- Facilitación de flujos de información que disminuyen los costos de transacción ex ante y aumentan el proceso de difusión de innovaciones.

- Imposición de contratos en forma más efectiva y más barata, que implica costos de transacción menores.

- Capacidad mejorada para la acción colectiva, especialmente con respecto a la producción o al mantenimiento tanto de bienes públicos como de recursos comunales.

- Mecanismos de seguro informal mutuo, que reducen los márgenes de incertidumbre.

- Fomento de sinergia con actores externos, ya sean organizaciones gubernamentales, no gubernamentales o privadas.

El término "capital social" aparece por primera vez en el transcurso del año 1916, cuando Lyda Hanifan lo utiliza para describir cierto comportamiento comunitario propio de las escuelas rurales, el cual define como:

Aquellos componentes intangibles que cuentan muchísimo en las vidas cotidianas de la gente, específicamente, la buena voluntad, el compañerismo, la empatía y las relaciones sociales entre individuos y familias que conforman una unidad social [...] Si un individuo establece contactos con sus vecinos y éstos con otros vecinos, se producirá una acumulación de capital social que, posiblemente, satisfaga al instante sus necesidades y entrañe, a la vez, un poder social suficiente como para generar una mejora sustantiva en las condiciones de vida de toda la comunidad (Hanifan, 1916: 130).

Posteriormente, el término capital social desaparece de la escena académica, hasta que en los años 1950 es recuperado por sociólogos urbanos canadienses - Sleely, Sim y Loosely- (Lanzini, 2008). En los años 1960, la noción de capital social es utilizada para explicar fenómenos relativos al intercambio y para afrontar discusiones sobre temas urbanos. Luego, durante los años 1970, Loury y Light utilizaron la expresión para analizar el problema del desarrollo económico en las áreas centrales de las grandes urbes; En todos estos casos el concepto se utiliza como paraguas para expresar la idea de vitalidad e importancia de los lazos entre individuos (Lanzini, 2008).

Más cercano en el tiempo, Robert Putnam rescata la expresión en sus estudios sobre participación cívica, instituciones y desarrollo económico definiéndolo como las "características de la organización social, confianza, normas y sistemas, que contribuyen a aumentar la eficiencia de la sociedad, facilitando las acciones coordinadas" (Putnam, 1993: 187). 
En términos generales, los autores que asumen esta visión sostienen que la cultura impregna todas las facetas de la actividad y el comportamiento, siendo expresión de las creencias, actitudes, valores, calificaciones e instituciones colectivas de cualquier grupo humano; desde esta perspectiva la idiosincrasia local proporciona los medios para crear una identidad colectiva y un sentimiento de pertenencia en los individuos, que se traduce posteriormente en un estímulo para la acumulación del capital en el territorio.

Partiendo de estos elementos se plantea la existencia de una estrecha relación entre cultura y desarrollo económico. Puede afirmarse entonces que "la cultura de un lugar afecta profundamente la forma en que su población actúa y reacciona frente al cambio tecnológico en función de sus creencias, conocimientos, valores culturales y habilidades" (Malecki, 1995: 18).

Desde esta visión, la propia existencia de una cultura local sólidamente asentada, genera una cierta autoestima y contribuye a vertebrar la sociedad local, favoreciendo per se el desarrollo económico y la innovación.

En este sentido, la cultura local, en tanto conjunto de valores e identidad compartida, contribuiría a la constitución y funcionamiento de redes sociales y empresariales basadas en la confianza mutua por las que puede circular información relevante para el crecimiento económico o, lo que resulta equivalente, incrementaría el capital social.

Dadas estas circunstancias, la estrategia de desarrollo territorial sustentada en esta visión de tipo comunitarista se caracteriza por incentivar intervenciones que buscan aumentar y/o mejorar la organización social del territorio, impulsando el empoderamiento de los actores locales.

Partiendo de esta idea, Velázquez Holguín (2008) analiza muy bien en que consiste la estrategia de fortalecimiento del capital social:

Al sujeto de desarrollo lo fortalece el ejercicio de sus capacidades y lo debilita la falta de uso [de las mismas]. Así como un músculo se minimiza e incluso se atrofia por el permanente ocio, los individuos se estancan o retroceden en su grado de desarrollo cuando no emplean a fondo su inteligencia y su voluntad para plantearse metas y alcanzarlas. En igual circunstancia, las comunidades locales se estancan cuando carecen de proyectos comunes que merezcan su compromiso (Velázquez Holguín, 2008: 259)

Habitualmente, las iniciativas comunitarias de este tipo son apadrinadas y financiadas por programas de cooperación internacional que involucran a distintos organismos multilaterales, siendo más habituales su ejecución en pequeñas localidades. En este sentido, el PNUD (Programa de Naciones Unidas para el Desarrollo) define muy bien el papel que le cabe a las organizaciones sociales en las estrategias desarrollo económico impulsadas por el organismo: 
[S]e considera que las organizaciones de la sociedad civil se caracterizan por su potencial para contribuir a dar respuesta a las necesidades, su capacidad de innovación y establecimiento de relaciones directas, su estímulo a la participación, su relación costo-eficiencia y la responsabilidad en la rendición de cuentas de sus acciones (PNUD-BID, 1998: 15).

Dentro de este esquema de promoción, las técnicas privilegiadas para generar o revitalizar capital social comunitario son aquellas que trabajan sobre elementos de identidad compartida y sobre la memoria histórica, reforzadas por sesiones de capacitación, créditos y subsidios a las organizaciones territoriales con el objetivo de implementar proyectos productivos de tipo asociativos.

A través de estas iniciativas, se pretende aumentar la capacidad de autogestión en el territorio, reforzando liderazgos y solucionando conflictos. A su vez y de acuerdo al discurso imperante, el hecho de privilegiar la acción comunal por sobre la estatal permite la ruptura de relaciones paternalistas y clientelares muy características de algunos espacios locales.

Por último, existen diversas experiencias de esta naturaleza en América Latina que han sido documentadas por universidades y organismos nacionales e internacionales. A modo de ejemplo, podemos citar los casos del programa de desarrollo rural para pequeños productores de Zacapa y Chiquimula en Guatemala (PROZACHI) y el proyecto de productivo y cultural "Paseo Lanchas Amarillas" en la localidad de Mar del Plata Argentina.

\section{Críticas y reflexiones sobre la corriente regional participativa. Alcances y limitaciones}

Aun cuando no se puede desconocer que la corriente regional participativa ha significado un avance en relación con las visiones centralizadas sobre las que se había focalizado la discusión en materia de desarrollo regional, también es posible esbozar algunas dudas en cuanto a la consistencia teórica y la viabilidad de implementación de sus propuestas, en especial cuando se las considera a la luz de las modalidades de organización y de funcionamiento que han venido adoptando los países Latinoamericanos.

En relación a la consistencia teórica de la misma, resulta importante destacar en primer lugar, la llamativa simplificación que esta hace respecto a las consecuencias que la creciente internacionalización de los mercados tiene sobre la unificación de los circuitos de capital y sobre las modalidades y alcances de los procesos de generación, apropiación y utilización del excedente económico.

Como bien sostienen Amin y Robins (1994), la resurrección de la comunidad parece enmascarar la creciente importancia que adquieren los vínculos entre lo global y lo local, ya que en una economía crecientemente integrada, la revaloriza- 
ción del empresario regional no puede oscurecer la influencia creciente que ejerce el capital global industrial y financiero. En este contexto, las grandes empresas son el centro privilegiado de la acumulación y en consecuencia constituyen "agentes determinantes de la configuración de la economía y el espacio" (Gatto y Ferraro, 1997: 14).

Esta lógica de creciente expansión de los capitales transnacionales trae aparejada la absorción de empresas regionales, que pierden grados de autonomía decisional y por lo tanto capacidad de reinvertir excedentes en el territorio. A su vez, incluso aun existiendo la posibilidad de supervivencia de este tipo de firmas, resulta dudoso suponer que si alcanzan ellas cierto umbral crítico de crecimiento en sus actividades no terminen desterritorializando también inversiones, insertándose de esta forma en la lógica de acumulación global. Una vez imbricadas en esta dinámica es factible suponer que tanto las ganancias como las inversiones se filtren hacia fuera de la región originaria, buscando una mayor valorización ${ }^{5}$.

Por otro lado, otra cuestión a analizar en este punto radica en discutir el papel que puede jugar la innovación en el desarrollo de territorios periféricos. Generalmente en las zonas marginales y deprimidas abundan las empresas especializadas en ramas tradicionales, poco intensivas en el uso de tecnología; en estos ámbitos la estrategia empresarial predominante es defensiva, es decir, apunta a la supervivencia de la firma como forma de autoempleo más que a la disputa de nuevos mercados.

En este sentido, cabe preguntarse cuál puede ser la capacidad innovadora de las pequeñas empresas dominantes en estas áreas, habida cuenta su limitada capacidad financiera y de recursos humanos. Como bien se destaca en la literatura especializada, estas cuestiones también tienen que ver con el contexto para la creación de empresas que se puede encontrar en América Latina, el cual difiere mucho del que ofrecen las economías desarrolladas.

En las economías del primer mundo los emprendedores utilizan la identificación de oportunidades de negocio como motor principal para la creación de empresas ya que existe una demanda sostenida y cada vez más diversificada de productos, mientras que, en el caso latinoamericano la demanda suele ser mucho más volátil y concentrada en menos rubros, achicando los márgenes de rentabilidad para nuevos negocios y generando condiciones de elevada incertidumbre para la supervivencia de cualquier empresa. Esto lleva, en términos, de Acs y Amorós (2008), a que los emprendedores latinoamericanos sean en su mayoría personas que han sido excluidas del mercado de trabajo y que intentan generarse un ingreso, más que individuos con vocación para los negocios.

\footnotetext{
${ }^{5}$ Esta afirmación coincide con la idea de "cuasi-integración vertical desintegrada", propia de países con centros territoriales consolidados y zonas deprimidas (Leborgne y Lipietz, 1988).
} 
Además de problemas por el lado de la demanda, también se observan en nuestro continente dificultades de financiamiento, ya que las posibilidades de acceder a un crédito significativo por parte de las firmas es mucho más baja que en Europa o Estados Unidos. Según Studart y Suaznábar (2004), el 80\% de los emprendedores latinoamericanos utiliza sus propios recursos para iniciar su empresa y debido a la falta generalizada de crédito barato, optan por mecanismos de financiación alternativos: adelantos de clientes, créditos de proveedores, retrasos en los pagos de impuestos, servicios o salarios y compra de equipos de segunda mano. Esto se traduce en mayores condiciones de informalidad, deterioro en la calidad de los productos fabricados y atraso tecnológico. A estas dos cuestiones debe sumársele necesariamente la falta de un entorno organizacional dinámico que preste servicios adecuados (técnicos, contables, legales, logísticos, etc.) a las empresas para mejorar sus capacidades competitivas.

En segundo lugar, otro aspecto sobre el cual cabe hacer consideraciones es el que se refiere a la visión que la corriente participativa plantea sobre la sociedad regional y sobre la estructura del Estado. Habitualmente este enfoque privilegia una aproximación de la organización social que minimiza la importancia de los conflictos ya sean estos de clase, religiosos o raciales; esta percepción de una sociedad casi uniforme no coincide con la realidad de los países latinoamericanos, donde existen importantes desigualdades de ingresos y/o étnicas.

Respecto a la primera clase de conflictos, resulta de importancia destacar que detrás de este paradigma subyace una visión idealizada de lo que realmente es un espacio local en una sociedad de clases; en este ámbito, como en el nacional, existen relaciones sociales que articulan intereses de propietarios de los medios de producción y de trabajadores y donde se despliegan, a su vez, estrategias para la valorización del capital, que pueden traducirse en procesos de explotación de la mano de obra. El olvido que este enfoque hace de dichas tensiones, las cuales se reproducen hacia dentro de la estructura del Estado, dificulta entender los procesos de toma de decisiones a nivel gubernamental. Debido a estas circunstancias, la mayoría de los trabajos relativos a la problemática local se apoyan en un planteamiento de tipo voluntarista o ingenuo del Estado, haciendo más hincapié en lo que el mismo debe hacer para conducir mejor el proceso de desarrollo que en entender la naturaleza y la función de éste en las sociedades capitalistas ${ }^{6}$.

\footnotetext{
${ }^{6}$ Respecto a este punto, De Mattos (1986) sostiene que uno los vicios fundamentales de los enfoques de desarrollo local es anteponer la visión del Estado que se quiere o se necesita, a la realidad del Estado que se tiene. En este sentido, ya Coraggio (1980) manifestaba que la idea de un Estado que actúa como garante y organizador de la permanencia y reproducción de una forma de organización en la que un determinado grupo social realiza su hegemonía es sistemáticamente soslayada en las fundamentaciones que acompañan las propuestas más tradicionales y ortodoxas de desarrollo local.
} 
Con respecto a la viabilidad de las propuestas planteadas por esta corriente, Díez (2004) analiza las limitaciones de implementación que presenta la estrategia más de corte "municipalista" en América Latina, destacando las siguientes:

- Inexistencia de un marco legal adecuado: no existe en la región un marco legal que contemple la existencia de una política de desarrollo local que contenga estrategia, objetivos, acciones, métodos de gestión y formas de financiación. La política de desarrollo local no se entiende como una política de Estado, sino que surge más bien como respuesta de las comunas y las regiones a problemas planteados por el ajuste productivo.

- Autonomía reducida de la acción local: se carece de un marco general de apoyo que institucionalice la autonomía local y la dote de los recursos presupuestarios imprescindibles. Cuando el proceso de descentralización y devolución de competencias a las comunidades no se ha extendido o hecho operativo en todo el territorio nacional, los gobiernos locales ven reducida su autonomía de acción, por lo que la política no puede generalizarse en todos los territorios y queda circunscripta a aquellos municipios más dinámicos y emprendedores.

- Ausencia de organismos nacionales que incentiven el desarrollo endógeno y/o problemas de interlocución para canalizar iniciativas: existe en Latinoamérica una carencia de canales institucionales a nivel nacional que fomente específicamente el desarrollo territorial; los gobiernos locales se encuentran con que los recursos disponibles figuran en partidas presupuestarias establecidas para alcanzar metas diferentes de las iniciativas planteadas por ellos, o con el hecho de que varias reparticiones públicas nacionales comparten competencias, intereses y responsabilidades en la solución sus problemas.

- Insuficiencia de recursos humanos adecuados para la gestión territorial: a escala municipal es frecuente la abundancia de personal de baja calificación y la carencia de recursos humanos con los conocimientos y experiencias necesarios para gestionar adecuadamente las nuevas políticas locales. Las debilidades de este tipo incluyen tanto la carencia de capacidades gerenciales en los niveles de conducción como de conocimientos técnicos actualizados en los cuadros administrativos y profesionales.

- Clientelismo, corrupción, problemas tecnológicos y de financiamiento: los municipios de América Latina son a menudo escenarios de clientelismo. Los modelos políticos tradicionales desempeñan un gran papel, y la cultura local no suele disponer de rasgos emprendedores sino más bien de aquellos derivados de la lógica del subsidio. A su vez, las comunas oponen gran resistencia a las iniciativas de modernización administrativa, principalmente en las regiones más atrasadas y periféricas, precisamente 
donde las mismas debieran aplicarse en mayor medida de acuerdo a lo promovido por el discurso imperante. Por su parte, en muchos territorios los servicios económicos (por ejemplo, permisos de construcción y puesta en marcha de empresas) se obtienen sobre la base de pagos ilegales y/o se retrasan o entorpecen a causa de obstáculos burocráticos. Además, las municipalidades son con frecuencia demasiado pequeñas, su financiamiento e ingresos propios escasos, la dependencia de normas y recursos externos excesiva y sus estructuras administrativas tecnológicamente atrasadas.

- Dificultades para organizar redes empresariales a partir de instrumentos diseñados localmente: no existe evidencia sistemática a escala continental que dé cuenta de la conformación de tramas empresarias regionales a partir de instrumentos diseñados a nivel municipal. Sólo existen casos sumamente heterogéneos en distintas ramas industriales que, además, evolucionan hacia la configuración de otro tipo de redes en las que las grandes empresas multinacionales cobran protagonismo.

Por su parte, dentro de esta vertiente crítica o reflexiva sobre la propuesta municipalista, autores como Vainer (2000a; 2000b) discuten cuestiones instrumentales, como la creciente influencia del marketing en la gestión y el planeamiento de las ciudades, que tiende a darle, desde su punto de vista, una impronta de tipo neoliberal a la políticas implementadas.

En relación a este punto y refiriéndose al accionar de los consultores en la materia, el autor sostiene:

Para ellos vender la ciudad es necesariamente, vender aquellos atributos que constituyen de una manera $u$ otra, insumos valorizados por el capital transnacional: espacios para convenciones y ferias, parques industriales y tecnológicos u oficinas de asesoramiento para empresarios. Esta apertura al mercado internacional es, a su vez completamente selectiva: no se quieren visitantes y usuarios en general de la ciudad y muchos menos inmigrantes pobres expulsados de otros países; se quiere visitantes y usuarios solventes (Vainer, 2000a: 80).

Desde esta perspectiva, el derecho al uso de las ciudades pasa a ser directamente proporcional al índice de solvencia de los extranjeros y visitantes.

A su vez, en el marco de dichas reflexiones Vainer (2000b) sostiene que las estrategias de desarrollo local y de competitividad urbana se han estructurado sobre la articulación de tres analogías constitutivas: a) la ciudad es concebida como una mercancía que se vende en un mercado extremadamente competitivo, en el cual otras localidades también están a la venta; b) la ciudad es concebida como una empresa, en tanto constituye un agente económico que actúa en un contexto de mercado y que encuentra en él la regla y el modelo de planificación de sus acciones; 
y c) la ciudad es considerada una patria, ya que para su venta en un mercado globalizado resulta necesario construir consenso en torno al proyecto que se está promocionando. De acuerdo a este autor, estas tres analogías terminan por desvirtuar la idea de ciudad como espacio público, es decir como un terreno no sometido a las leyes del mercado, y como ámbito democrático, entendido como un lugar en el cual puede ejercerse el disenso.

Por otro lado, respecto a la eficiencia de los mecanismos de cooperación público-privada en la promoción de la competitividad urbana, autores como Harvey (1995) consideran que en su mayor parte constituyen sólo aportes públicos para financiar emprendimientos de grupos empresariales privados, es decir, mecanismos de transferencia de recursos financieros del Estado hacia sectores concentrados, sin generar efectos trascendentes en la economía local.

En este sentido, él mismo sostiene:

Mucha de la articulación público privada que existe hoy en día puede resumirse en una subvención a consumidores afortunados, a firmas y a grupos directivos, para que permanezcan en la ciudad a costa del consumo colectivo local de la clase trabajadora y de los pobres (Harvey, 1995: 49).

Respecto a esta cuestión, la evidencia latinoamericana muestra que la planificación estratégica se ha constituido, en numerosos casos, en el instrumento utilizado para legitimar estos procesos de transferencia, forzando el consenso social sobre proyectos específicos a través de diversos mecanismos, entre los que podemos citar: el control de agenda, el manejo discrecional de la convocatoria a las fuerzas vivas de la sociedad civil o el control exclusivo de algunos grupos de interés sobre determinadas líneas estratégicas del plan en cuestión ${ }^{7}$.

A su vez, en el marco de las críticas instrumentales a la política de desarrollo local, también puede afirmarse que existen ciertas dudas sobre las posibilidades de producir o revitalizar capital social comunitario de forma artificial, es decir a través de mecanismos de intervención pública.

Curiosamente, estas incertidumbres provienen de uno de los autores más destacados en el análisis de estas temática, Robert Putnam. En relación a esta cuestión, Putnam (1993) concluye que, "[e]n la construcción de instituciones, el tiempo se mide en décadas y en el caso de la creación de normas de cooperación y de participación cívica, la edificación es aún más lenta" (Putnam, 1993: 89). Esta visión incrédula refleja la creencia de que, en cualquier localidad existen mecanismos de retroalimentación que refuerzan constantemente las normas y los comportamientos existentes, llevando a todo el sistema sociocultural a un equilibrio social positivo,

\footnotetext{
${ }^{7}$ Más detalles sobre estas cuestiones puede encontrarse en Mintzberg (1994), Dreyfuss y Marchand (1995), Harvey (1996), Vainer (1996) o Compans (1998).
} 
donde existe acumulación de capital social o a uno negativo a partir del cual se genera una sociedad "acívica".

Según el autor, en este último caso "la desconfianza y la traición mutua, la dependencia vertical y la explotación [...] se refuerzan en círculos viciosos interminables que repercuten negativamente sobre el desarrollo económico" (Putnam, 1993: 177, cursiva propia). Desde esta perspectiva entonces, cabe considerar el interrogante de si las políticas de índole comunitarista aplicadas en el continente están generando verdaderamente capital social o sólo promoviendo ocasionales formas de cooperación, sustentadas exclusivamente en la presencia de fondos - generalmente internacionales- para financiar proyectos.

Por su parte, autores como Bustelo (1998) sostiene la necesidad de llamar la atención sobre la evidente limitación que presentan numerosas organizaciones de la sociedad civil a la hora de acreditar una efectiva representación social, que permita garantizar una transparente asignación de los recursos públicos destinados al desarrollo. Según este autor:

En América Latina es común encontrar dirigentes políticos enmascarados detrás de organizaciones sociales, ya sea cuando crean su propia ONG para captar recursos o cuando se insertan en alguna institución reconocida para presentarse como miembros de la dirigencia social; a este problema típico se suman los problemas de legitimidad interna en las organizaciones, la falta de consensos y la presencia de liderazgos no revalidados (Bustelo, 1998: 5).

Por último, resulta importante evaluar el impacto que las nuevas políticas tienen sobre la distribución territorial de los factores productivos y las actividades económicas en el continente. Si bien en la actualidad no existen indicadores económicos sobre Producto Bruto Geográfico que permitan hacer un análisis de convergencia regional $^{8}$ para cada uno de los países de América Latina, la evidencia sobre una concentración territorial de la población en torno a las ciudades principales muestra cierta tendencia que no ha podido quebrarse a lo largo de los años (Cuadro 3$)^{9}$.

Los datos publicados por CELADE arrojan que, entre los años 1990 y 2000 , período ya de pleno auge y difusión de las políticas de desarrollo endógeno en el continente, la distribución espacial de la población no registra cambios significativos en relación a los períodos históricos en los cuales ha regido una visión del desarrollo mucho más centralizada. Incluso la concentración se agudizó en países

\footnotetext{
${ }^{8}$ Iván Silva Lira (2003) realizó un intento de medir la convergencia de ingresos entre regiones de distintos países de América Latina obteniendo resultados poco exitosos. El estudio consideró tanto convergencia sigma como convergencia beta y abarco a regiones de Brasil, Bolivia, Chile, México y Colombia. De acuerdo a lo expuesto por el autor, las mayores divergencias se encuentran en Perú, seguido de Brasil, Chile y México.

${ }^{9}$ A la fecha, no existen datos estadísticos disponibles de los Censos Nacionales del año 2010.
} 
como Ecuador, donde la población de Quito y Guayaquil paso de ser el $44 \%$ del total nacional en 1990 al $46.7 \%$ en el 2000 (Cuadro 3).

Cuadro 3. América Latina y El Caribe. Evolución del peso relativo de la población de las DAM metropolitanas principales sobre la población nacional

\begin{tabular}{|l|l|l|l|l|l|l|}
\hline Divisiones administrativas mayores (DAM) & $\mathbf{1 9 5 0}$ & $\mathbf{1 9 6 0}$ & $\mathbf{1 9 7 0}$ & $\mathbf{1 9 8 0}$ & $\mathbf{1 9 9 0}$ & $\mathbf{2 0 0 0}$ \\
\hline Buenos Aires & 45.6 & 48.6 & 50.3 & 49.3 & 47.7 & 45.8 \\
La Paz & 31.4 & $\mathrm{~s} / \mathrm{d}$ & 31.8 & $\mathrm{~s} / \mathrm{d}$ & 29.6 & 28.4 \\
Rio de Janeiro & 9.1 & 9.1 & 9.7 & 9.5 & 8.5 & 8.5 \\
Sao Pablo & 17.7 & 17.6 & 19.1 & 21.0 & 21.7 & 21.8 \\
Región Metropolitana (Santiago de Chile) & 28.7 & 32.1 & 35.5 & 38.1 & 39.4 & 40.1 \\
Cundinamarca (Santa Fé de Bogotá) & 19.5 & 16.2 & 17.6 & 19.3 & 19.9 & $\mathrm{~s} / \mathrm{d}$ \\
San José (Costa Rica) & 35.2 & 36.5 & 37.1 & 36.8 & $\mathrm{~s} / \mathrm{d}$ & 35.3 \\
La Habana & 34.0 & $\mathrm{~s} / \mathrm{d}$ & 27.0 & 25.9 & $\mathrm{~s} / \mathrm{d}$ & $\mathrm{s} / \mathrm{d}$ \\
Pichincha (Quito) & 12.1 & 12.9 & 15.2 & 17.0 & 18.1 & 19.8 \\
Guayas (Guayaquil) & 18.2 & 21.5 & 23.2 & 25.0 & 25.9 & 26.9 \\
San Salvador & 16.0 & 18.4 & 20.6 & $\mathrm{~s} / \mathrm{d}$ & 29.5 & $\mathrm{~s} / \mathrm{d}$ \\
Guatemala & 15.7 & 18.9 & 21.5 & 21.7 & 21.8 & $\mathrm{~s} / \mathrm{d}$ \\
Asunción & 27.1 & 28.5 & 29.3 & 31.4 & 32.9 & $\mathrm{~s} / \mathrm{d}$ \\
Lima & 14.6 & 22.7 & 28.0 & 30.5 & 31.9 & $\mathrm{~s} / \mathrm{d}$ \\
Distrito Capital/Miranda/Vargas (Caracas) & 19.6 & 23.3 & 25.3 & 24.1 & 22.0 & 19.4 \\
Distrito Nacional (Santo Domingo) & 11.2 & 15.3 & 20.3 & 27.5 & 30.1 & $\mathrm{~s} / \mathrm{d}$ \\
Ciudad de Panamá & 30.8 & 34.6 & 40.4 & 44.8 & 46.0 & $\mathrm{~s} / \mathrm{d}$ \\
Managua (Nicaragua) & 15.3 & 20.8 & 25.9 & $\mathrm{~s} / \mathrm{d}$ & 25.1 & $\mathrm{~s} / \mathrm{d}$ \\
Distrito Federal (México) & 17.2 & 19.4 & 22.2 & 24.5 & 22.2 & 22.3 \\
Cortés (Tegucigalpa) & 9.1 & 10.6 & 13.9 & 14.8 & $\mathrm{~s} / \mathrm{d}$ & $\mathrm{s} / \mathrm{d}$ \\
Departement d L'Ouest (Puerto Príncipe) & 21. & $\mathrm{~s} / \mathrm{d}$ & 27.9 & 30.7 & $\mathrm{~s} / \mathrm{d}$ & $\mathrm{s} / \mathrm{d}$ \\
\hline
\end{tabular}

Fuente: CELADE y base de datos DEPUALC (Distribución Espacial de la población y urbanización para América Latina y el Caribe), 2001.

De acuerdo a De Mattos (1999), la concentración poblacional en Áreas Metropolitanas implica la polarización de toda una amplia gama de actividades productivas: industria, construcción, servicios financieros, servicios al productor, educación superior y servicios vinculados a productos y actividades globales (nuevas tecnologías, moda, hotelería, gastronomía, etc.). En términos generales, la tendencia en América Latina parece evidenciar la consolidación de capitales o ciudades principales con cobertura regional, suburbanizadas y policéntricas, de límites imprecisos, configuradas como archipiélagos y cuya dinámica expansiva incorpora a pequeños centros urbanos aledaños y áreas rurales que pasan a formar parte de un extenso periurbano.

A modo de ejemplo, pueden citarse los casos de Buenos Aires y Santiago de Chile. Actualmente, en la región Metropolitana (RMBA) de Buenos Aires se con- 
centra el $53 \%$ del PBI y el 35\% de la población argentina; esta área contiene a la ciudad capital que alcanza un $25 \%$ del PBI y un $8.3 \%$ de la población nacional. En cuanto a Santiago de Chile, ésta cuenta con un nivel de primacía similar, alcanzando un $47 \%$ del PBI y 39\% de la población del país (véase Moncayo Jiménez, 2002).

Como puede observarse, estos resultados hacen dudar sobre los efectos concretos que las políticas de "abajo hacia arriba" pueden tener sobre la acumulación de capital en territorio periféricos, de forma que pueda promover la desconcentración de actividades o algún grado de convergencia de ingresos entre regiones de un mismo país.

\section{Conclusiones: la experiencia latinoamericana y la necesidad de construcción de un nuevo enfoque capaz de superar controversias}

En América Latina, las políticas de desarrollo regional comienzan a ejecutarse con continuidad a partir de la década de 1950, al calor de la segunda posguerra. Con anterioridad, la planificación, entendida como un procedimiento idóneo para racionalizar el proceso de decisiones y acciones requeridas para la ejecución de un determinado proyecto político, no había logrado mayor aceptación oficial. Esto se debía principalmente al hecho de que hasta ese momento se la identificaba con los procedimientos utilizados en la conducción del proceso soviético, el cual era observado con poca simpatía por la mayor parte de los países de la región.

Esta situación comienza revertirse a mediados de los 1950 y principios de los 1960, debido principalmente a dos cuestiones fundamentales: en primer lugar, a la difícil situación económica, política y social que vivían las naciones latinoamericanas, lo cual obligaba a las administraciones públicas a buscar mecanismos alternativos al mercado para solucionar conflictos. En segundo lugar, al hecho de que ya muchas naciones occidentales habían comenzado a adoptar y difundir modalidades de planificación alternativas a la de origen ruso, lo cual contribuyó a reducir la resistencia al instrumento.

A su vez, la preocupación por definir acciones de incidencia regional específica tenía su origen y fundamento en la existencia de ciertos aspectos que se presentaban con diversa intensidad en distintas partes del territorio nacional y que eran percibidos como problemas por los agentes con responsabilidades en el Estado. En este sentido, tales inconvenientes se vinculaban con los obstáculos a la transmisión de los impulsos de desarrollo a través del espacio y el fracaso en el establecimiento automático del equilibrio en la distribución de la población, los recursos y las actividades económicas.

Estas dificultades, relacionadas con disparidades regionales y concentración territorial de actividades y población hacían referencia a fenómenos que en forma sintética podrían resumirse en: a) distribución desigual de las fuerzas productivas; $b$ ) desarrollo heterogéneo de dichas fuerzas en el territorio; c) ritmos interregionales de 
acumulación, crecimiento, distribución y consumo divergentes; d) condiciones para la satisfacción de las necesidades básicas de la población distintas según el territorio que se trate; y e) escasa integración económica entre regiones.

Para la solución de estas adversidades, los Estados nacionales implementaron una serie de políticas de arriba hacia abajo que buscaban esencialmente aumentar la inversión en el territorio a través de mecanismos de big push; la máxima expresión de esta idea estuvo ejemplificada en la noción de polo de crecimiento. En términos generales, los resultados obtenidos a partir de estas iniciativas fueron sumamente modestos. Los proyectos generados durante aquellos años se transformaron en enclaves típicos con importantes fugas hacia centros industriales de países desarrollados, sin alterar significativamente el ingreso regional.

A su vez, la ausencia de resultados concretos significativos en materia de desarrollo, obligaron a una importante revisión de los fundamentos sobre los cuales se centraba la práctica de la planificación. A partir de este proceso de crítica y reflexión, surge una nueva corriente de pensamiento que promueve un mayor involucramiento de los niveles inferiores del Estado y de la sociedad civil en el diseño de políticas de desarrollo territorial. La mayor parte de los autores adherentes a este enfoque desplazan el centro del análisis de los aspectos productivos (fundamentalmente de carácter industrial) y espaciales (básicamente urbanos), hacia el papel que cumplen o deberían cumplir los actores locales en el proceso de desarrollo. Además, se plantea la necesidad de reinvertir los excedentes generados a nivel regional y se apela a que los empresarios locales innoven, por considerar que el progreso técnico es el instrumento más idóneo para incentivar el poder de mercado y el incremento de las ganancias empresarias.

Lamentablemente y al igual que en el caso anterior, comienzan a observarse importantes limitaciones en el enfoque pese a la fuerte difusión que diversos organismos internacionales hacen de la propuesta. La inexistencia de un marco legal adecuado para las iniciativas, la baja autonomía de la acción local, la insuficiencia de recursos humanos y técnicos adecuados para la gestión, el olvido de las tensiones sociales, la desaparición o inacción de empresarios regionales, el clientelismo, la corrupción y la imposibilidad de crear artificialmente capital social son algunas de las críticas más fuertes que esta nueva corriente viene soportando a lo largo de estos últimos años. En cuanto a los resultados de política, los mismos son tan modestos como los registrados en procesos anteriores, ya que no se ha logrado revertir la tendencia a la concentración territorial de actividades productivas y de población.

Estas situaciones muestran cierto agotamiento del planteamiento, que obliga necesariamente a repensar la estrategia de desarrollo territorial en el continente, a partir de un análisis más profundo de las debilidades registradas en la planificación denominada regional participativa. Razonar sobre las mismas implica avanzar en la construcción de un nuevo marco conceptual, superador de la antinomia tradicional arriba-abajo, abajo-arriba. En este sentido, profundizar la discusión sobre la necesidad de una nueva forma de intervención territorial implica dejar de lado 
pasiones e incluso cierta actitud militante por parte de políticos e intelectuales, tanto a favor como en contra de la estrategia anterior. La revisión del instrumento supone además observar con mayor detenimiento las experiencias frustradas, buscando elementos en común que faciliten la comprensión de las circunstancias por las cuales la política de desarrollo a escala local en algunos territorios fracasa.

Respecto a esta cuestión, resulta de importancia entender mejor el proceso a partir del cual se diseña o se construye la estrategia y el rol que juegan los distintos actores territoriales y sus relaciones en la definición de la política, junto al papel que las instituciones formales e informales tienen en la acumulación de capital. A su vez, si existe consenso sobre el papel relevante que el empresario regional tiene que cumplir en el desarrollo, las políticas de planificación y promoción del mismo deberán incluir en forma más sistemática y con mayor rigurosidad conceptos y análisis propios de la economía industrial y de la economía espacial ${ }^{10}$. Esto implica incorporar con mayor frecuencia en la elaboración de planes estratégicos municipales a especialistas en estas áreas, que revaloricen las nociones de externalidad, economías de alcance y aglomeración, entre otras.

Por otro lado, el diseño de un nuevo marco conceptual capaz de superar controversias deberá constituirse al menos, sobre cuatro ejes fundamentales:

- En primer lugar, sobre la valoración positiva de la participación y la organización social en el diseño de estrategias de desarrollo económico local, pero reconociendo que las mismas deben darse en el marco de una estrategia nacional de carácter coherente y dotada de los recursos necesarios para garantizar su normal desenvolvimiento. Desde esta perspectiva, la descentralización y la participación son positivas, ya que cada municipio estará en condiciones de definir su patrón de desarrollo en base a ciertos lineamientos o ejes nacionales; dicho patrón será acompañado técnica y financieramente por los distintos niveles de gobierno. A su vez, en este punto resulta importante discutir qué papel se le dará a las organizaciones sociales en la instrumentación de la política y la definición de la estrategia, ya que es necesario garantizar la representatividad y la participación de todos los actores de la comunidad en el proceso de gestión. En este sentido, el diseño del instrumento no es una cuestión menor, ya que debe ser lo suficientemente flexible y transparente como para incorporar adecuadamente a los nuevos emergentes sociales surgidos en el continente, como ser grupos indígenas, asambleas barriales o piqueteros, entre otros.

\footnotetext{
${ }^{10}$ Un aporte interesante en esta materia puede encontrarse en los estudios realizados por el GREMI (Groupe Recherche Europeen sur les Milieux Innovateur) y en los documentos producidos por el Grupo Francés denominado "Dinámica de la Proximidad".
} 
- En segundo lugar, un eje pasará necesariamente por la recuperación de elementos conceptuales propios de las teorías tradicionales del subdesarrollo, reconociendo que muchas de sus categorías de análisis siguen vigentes, pero sin caer en planteamientos excesivamente deterministas que nieguen las posibilidades de crecimiento económico en el marco de sociedades capitalistas. Respecto a esta cuestión, es importante reconocer que muchas disparidades regionales han sido originadas por una desigual penetración espacial de las relaciones capitalistas de producción, que han llevado a la formación de estructuras territoriales donde coexisten en un mismo país actividades capitalistas avanzadas, con otras atrasadas o incluso precapitalistas, generando relaciones de dominación-dependencia. Estos procesos de dominación-dependencia se basan en movimientos interregionales de excedentes, que se producen principalmente a través de transferencias financieras, de procesos de intercambio desigual y de políticas tributarias mediante las cuales el Estado capta recursos para financiar actividades. Conocer y reconocer este tipo de relaciones y estos mecanismos de transferencia resulta fundamental para diseñar políticas que sean consistentes, de tal forma que no se sobredimensione la capacidad endógena que tienen algunos territorios periféricos para desarrollarse.

- En tercer lugar, un punto a abordar será necesariamente el reconocimiento de la capacidad del sector privado para dinamizar la economía, aún con las limitaciones propias de la actividad empresarial de estos espacios. Aquí será clave reconocer la diferencia entre favorecer la actividad empresarial y condicionar decisiones públicas locales a favor del capital, a través de una apropiación del aparato burocrático del Estado municipal en manos del sector privado. Para cumplimentar este objetivo resultará fundamental la transparencia de las cuentas públicas y el control de las esferas superiores de gobierno y de la sociedad civil.

- Por último, en el enfoque a construir se debe aceptar explícitamente la existencia de tensiones sociales en el proceso de desarrollo económico basadas en la presencia de actores con diferentes capacidades y diferentes niveles de negociación. En este punto, el papel del Estado local resultará crucial, ya que deberá ser capaz de mediar entre intereses divergentes, arbitrando los medios necesarios para solucionar conflictos, de tal forma de garantizar, en todos los ámbitos, el cumplimiento de los derechos de los sectores más débiles y vulnerables de la sociedad. 


\section{Bibliografía}

Acs, Zoltan, y Amorós, José (2008) "Entrepreneurship and Competitiveness Dynamics in Latin America". Jena Economic Research Papers, vol. 59, núm. 3, 137.

Aghion, Philippe, y Howitt, Peter (1992) "A Model of Growth through Creative Destruction”. Econometrica, vol. 60, núm. 2, 323-351.

Amin, Ash, y Robins, Kevin (1994) "El retorno de las economías regionales. Geografía mítica de la acumulación flexible", en G. Benko y A. Lipietz (eds.) Las regiones que ganan. Distritos y redes. Los nuevos paradigmas de la geografia económica. Valencia: Edicions Alfons el Magnánim / Generalitat Valenciana / Diputació provincial de Valéncia.

Arocena, José (1997) "Lo global y lo local en la transición contemporánea". Cuadernos del CLAEH. Montevideo: Centro Latinoamericano de Economía Humana (CLAEH), vol. 22, núm. 78-79.

Baltar, Fabiola (2010) Factor empresarial y flujos migratorios argentinos a España. Una perspectiva económica. Tesis doctoral, Universidad Rovira i Virgili.

Barreiro, Fernando (1988) "Los agentes del desarrollo: una reflexión sobre el desarrollo local y sus protagonistas". Cuadernos del CLAEH, Montevideo: Centro Latinoamericano de Economía Humana (CLAEH), vol. 13, núm. 45-46.

Bastiaensen, Cristian (2001) "Capital social y financiamiento para el desarrollo rural local en Nicaragua: perspectivas institucionales sobre desempeño e impacto", en H. Clemens y R. Ruben (eds) Nueva Ruralidad y política agraria. Caracas: Nueva Sociedad, 45-76.

Bertolotti, María Isabel, y Lasta, Carlos (2005) "Proyecto productivo y cultural "Paseo Lanchas Amarillas": espacio múltiple económico y social", en 3er Foro Federal de Investigadores y Docente. La Universidad y la Economía Social en el Desarrollo Local. Buenos Aires: Ministerio de Desarrollo Social de la Nación, 101-107.

Boisier, Sergio (1979) “¿Qué hacer con la planificación regional antes de medianoche?". Revista de la CEPAL, Santiago de Chile: Comisión Económica para América Latina y el Caribe (CEPAL), núm. 7, 135-170.Boisier, Sergio (1982) Política Económica, organización social y desarrollo regional. Santiago de Chile: ILPES.

Boisier, Sergio (1985) "Un difícil equilibrio: centralización y descentralización en la planeación regional”. Revista el Trimestre Económico, México: Fondo de cultura económico, vol. 52, núm. 205, 195-224.

Boisier, Sergio (1993) "Desarrollo regional endógeno en Chile. ¿Utopía o necesidad?". Ambiente y Desarrollo, Santiago de Chile: CIPMA, vol. 9, núm. 2, 35-63.

Bosma, Niels, y Schutjens, Veronique (2009) "Mapping Entrepreneurial Activity and Entrepreneurial Attitudes in European Regions". International Journal of Entrepreneurship and Small Business, vol. 7, 191-213. 
Boudeville, Jacques (1965) Los espacios económicos. Buenos Aires: EUDEBA. Buarque, Sergio (1999) Metodología de Planejamento do Desenvolvimento Local e Municipal Sustentável. Recife: IICA.

Bustelo, Eduardo (1998) "El abrazo. Reflexiones sobre las relaciones entre el Estado y los organismos no gubernamentales". Revista de Ciencias Sociales, Universidad Nacional de Quilmes, núm. 9, 61-72.

Calatrava Requena, Javier (1992) "El turismo rural como recurso endógeno en el desarrollo local", en C. del Canto (comp.) Desarrollo rural: ejemplos europeos. Madrid: IRYDA, 18-45.

Callejón, María (2003) "En busca de las economías externas”. Ekonomiaz, núm. 53, 75-89.

CELADE (2001) "Urbanización y Evolución de la población urbana en América Latina 1950-1990". Boletín Demográfico. Santiago de Chile, vol. 33, núm. especial, 17-89.

Compans, Rose (1998) "Parceria público-privada na renovaçao urbana da Zona Portuaria do Rio de Janeiro". Cuadernos de IPPUR, Río de Janeiro: Universidade Federal do Rio de Janeiro, vol. 12, núm. 1, 79-105.

Coraggio, José (1980) "Las bases teóricas de la planificación regional en América Latina (un enfoque crítico)". Revista Demografía y Economía, México: El Colegio de México, vol. 14, 141-178.

Cotorruelo Menta, Romeo (2001) “Aspectos estratégicos del desarrollo local”, en A. Vázquez Barquero y O. Madoery (comps.) Transformaciones globales, instituciones y políticas de desarrollo local. Rosario: Homo Sapiens, 100-128.

Cuervo, Luis (1998) "Desarrollo económico local: leyendas y realidades". Territorios, Santa Fé de Bogotá: CIDER Universidad de los Andes, núm. 1, 9-24.

De Mattos, Carlos (1986) "Paradigmas, modelos y estrategias en la práctica latinoamericana de desarrollo regional". Pensamiento Iberoamericano, Madrid: Agencia Española de Cooperación Iberoamericana, núm. 10, 15-41.

De Mattos, Carlos (1999) "Santiago de Chile, globalización y expansión metropolitana: lo que existía sigue existiendo". Revista EURE, Santiago de Chile: Instituto de Cooperación Iberoamericana, vol. 29, núm. 76, 29-56.

Díez, José (2004) "Transformaciones en la gestión municipal: el caso latinoamericano". Documento de Trabajo $N^{o} 6$. Bahía Blanca: Instituto de EconomíaUniversidad Nacional del Sur.

Dreyfuss, Laurence, y Marchand, Alain (1995) "Gouvernement local et légitimation : vers des républiques urbaines? ". Futur Antérieur, Paris, núm. 29, 71-102.

Durston, John (2002) El capital social campesino en la gestión del desarrollo rural: diadas, equipos, puentes y escaleras. Santiago de Chile: Comisión Económica para América Latina y el Caribe (CEPAL).

Espina, Alvaro (1994) "La estrategia de Hirschman revisitada". Claves de Razón Práctica, Madrid, núm. 39, pp. 51-55. 
Florida, Richard (2009) Las ciudades creativas. Por qué donde vives puede ser la decisión más importante de tu vida. Barcelona: Paidós.

García Delgado, Daniel (1997) Estado y Sociedad: la nueva relación a partir del cambio estructural. Buenos Aires: Norma.

Gatto, Francisco, y Ferraro, Carlos (1997) "Consecuencias iniciales de los comportamientos Pymes en el nuevo escenario de negocios en Argentina". Documento de trabajo CEPAL. Buenos Aires: Comisión Económica para América Latina y el Caribe (CEPAL), núm. 79.

Haddad, Pablo (1980) Participaçao, justicia social e planeamiento. Río de Janeiro: Zahar editores.

Hanifan, Lyda (1916). "The Rural School Comunity Center". Annals of the American Academy of Political and Social Science, Philadelphia: Sage Journals, núm. 67, 130-138.

Harvey, Dennis (1995) 'L'accumulation flexible par l'urbanisation : reflexions sur le «post modernisme» dans la grande ville américaine “. Futur Antérieur. Paris, núm. 29, 17-43.

Harvey, Dennis (1996) "Do gerenciamiento ao empresariamento : a transformaçao da administraçao urbana no capitalismo tardío". Espaço e Debates, Morumbi: Núcleo de Estudos Regionais e Urbanos (NERU), vol. 5, núm. 3, 48-64.

Hirschman, Albert (1957) The strategies of economic development. New Haven: Yale University Press.

Holmes, Thomas, y Schmitz, James (1990) "A Theory of Entrepreneurship and Its Application to the Study of Business Transfers". Journal of Political Economy, vol. 98, núm. 2, 265-294.

Kihlstrom, Richard, y Laffont, Jean Jack (1979) "A General Equilibrium Entrepreneurial Theory of Firm Formation Based on Risk Aversion". Journal of Political Economy, vol. 87, núm. 4, 719-748.

Kirzner, Israel (1973). Competition and Entrepreneurship. Chicago: University of Chicago Press.

Leborgne, Daniele y Lipietz, Alain (1988). "New technologies, new modes of regulation: some spatial implications". Environment and Planning: Society and Space, vol. 6, núm. 3, 263-280.

Lucas, Robert (1988) "On the Mechanics of Economic Development", Journal of Monetary Economics, vol. 22, núm. 1, 3-42.

Lanzini, Erica (2008) "Capital social: una herramienta básica para el desarrollo local”, en Agentes y Agenda para el desarrollo económico territorial y el empleo. [Puesto en línea por RED DETE-ALC (Red de desarrollo económico territorial y empleo para América Latina y el Caribe), URL: <http://www.detealc.org/_docs/1223402796,docs.pdf>, consultado el 04 de noviembre de 2008].

Malecki, Edward (1995) Technology and Economic Development. The Dynamics of Local, Regional and National Change. Londres: Longman. 
Mintzberg, Henry (1994) The rise and fall of strategic planning. Reconceiving roles for planning, plans, planners. New York: Free Press.

Moncayo Jiménez, Edgar (2002) Nuevos enfoques teóricos, evolución de las políticas regionales e impacto territorial de la globalización. Santiago de Chile: CEPAL, Serie Gestión Pública CEPAL, núm. 27.

Montecinos, Eghón (2005) "Los estudios sobre descentralización en América Latina: una revisión sobre el estado actual de la temática". Revista EURE, Santiago de Chile: Pontificia Universidad Católica de Chile, vol. 41, núm. 93, 78-93.

Müller, Sabine (2011) "Entrepreneurship and Regional Development: A Literature Review". Ponencia presented en el 56th Annual ICSB World Conference, Stockholm, Suecia.

Myrdal, Gunnar (1957) Economic Theory and Underdeveloped Regions. Nueva York: Harper Rose Publishers.

Neira Alva, Eduardo (1972) "El concepto de estrategia aplicado al desarrollo del Recóncabo de Bahía", en J. C. Funes (ed.) La ciudad y la región para el desarrollo. Caracas: Comisión de Administración Pública de Venezuela, 45-73.

Neira Alva, Eduardo (1974) "Las políticas de desarrollo regional en América Latina”. En ILPES (eds.) Planificación regional y urbana en América Latina. México DF: Siglo XXI editores, 53-89.

Nurske, Ragnar (1954) Problemas de la formación de capital en los países subdesarrollados. México DF: Fondo de Cultura Económica (FCE).

Paelinck, Jean (1963) "La teoría del desarrollo regional polarizado". Revista de Economía Latinoamericana, Caracas: Banco Central de Venezuela, núm. 9, 2143.

Perroux, Francois (1955) "Nòte sur la Notion de Pòle de Croissance". Economie Apliquée, vol. 8, 307-320.

PNUD-BID (Programa de Naciones Unidas Para el Desarrollo- Banco Interamericano de Desarrollo) (1998) El capital social: hacia la construcción del Índice de Desarrollo de la Sociedad Civil en Argentina. Buenos Aires: Edilab.

Putnam, Robert (1993) Making Democracy Work: Civic Traditions in Modern Italy. Princeton: Princeton University Press.

Restrepo, Ignacio (1984) Las Truchas: ¿inversión para la igualdad? México DF: Editorial Océano.

Rosenstein-Rodan, Paul (1943) "Problems of industrialization of Eastern and South-Eastern Europe", Economic Journal. Fife: Royal Economic Society, vol. 53, 202-211.

Schumpeter, Joseph (1942) Capitalism, Socialism and Democracy. Nueva York, Harper and Row.

Silva Lira, Iván (2003) Disparidades, competitividad territorial y desarrollo local y regional en América Latina. Santiago de Chile: Comisión Económica para América Latina y el Caribe (CEPAL), Serie Gestión Pública CEPAL, núm. 33. 
Stöhr, Walter (1981) "Development from below: the bottom-up and periphery Inward development paradigm", en W. Stöhr y D. Fraser Taylor (eds) Development from above or below? The dialectics of regional planning in developing countries. Singapore: John Wiley \& Sons, 25-43.

Stöhr, Walter, y Todtling, Franz (1979) "Spatial equity: Some anti-theses to current regional development strategy", en H. Folmer y J. Oosterhaven (eds.) Spatial inequalities and regional development. AK Houten: Springer Netherlands, 133160.

Studart, Rogerio, y Suaznábar, Claudia (2004) "El acceso al financiamiento, un reto para la creación de empresas dinámicas", en H. Kantis (ed.) Desarrollo Emprendedor. América Latina y la experiencia internacional. Banco Interamericano de Desarrollo (IADB) y Fundes Internacional.

Travieso, Fernando (1971) “Ciudad Guayana: ¿Polo de crecimiento?”. Cuadernos de la Sociedad Venezolana de Planificación. Caracas, núm. 92-93, 67-98.

Vainer, Carlos (1996) Participation, Poverty and Environment in the Strategic Plan for the City of Rio de Janeiro. Conference on Urban Change: the environment and poverty. Nueva York: Cornell University.

Vainer, Carlos (2000a) "Patria, empresa e mercadoria: Notas sobre a estrategia discursiva do Planeamiento Estratégico Urbano", en O. Arantes, C. Vainer y E. Maricato (comps.) A cidade do pensamiento único: desmachando consensos, Petrópolis: Vozes, 75-104.

Vainer, Carlos (2000b) "Os liberais também fazem planejamento urbano? Glosas ao Plano Estratégico da Cidade do Río de Janeiro", en O. Arantes, C. Vainer y E. Maricato (comps.) A cidade do pensamiento único: desmachando consensos, $\mathrm{Pe}-$ trópolis: Vozes, 105-120.

Vázquez Barquero, Antonio (1995) "Desarrollo Económico: flexibilidad en la acumulación y regulación del capital", en A. Vázquez Barquero y G. Garófoli (eds.) Desarrollo económico local en Europa. Madrid: Colegio de Economistas de Madrid, 135-147.

Velázquez Holguín, Marco Antonio (2008) "El fortalecimiento del sujeto de desarrollo", en Agentes y Agenda para el desarrollo económico territorial y el empleo [Puesto en línea por RED DETE-ALC, URL: <http://www.detealc.org/_docs/1223402524,docs.pdf>, consultado el 04 de noviembre de 2008].

Von Haldenwang, Christian (2000) Nuevos conceptos de la política regional de desarrollo: aporte para la discusión Latinoamericana. Santiago de Chile: Comisión Económica para América Latina y el Caribe (CEPAL).

Wennekers, Sander, y Thurik, Roy (1999) "Linking Entrepreneurship and Economic Growth”, Small Business Economics, vol. 13, núm. 1, 27-56. 